\title{
Desempenho de cultivares de batata-doce para caracteres relacionados com o rendimento de raiz
}

\author{
Giovani Olegario da Silva *1, Fabio Akiyoshi Suinaga², Rubens Ponijaleki , Geovani Bernardo Amaro ${ }^{2}$ \\ http://dx.doi.org/10.1590/0034-737X201562040007
}

\section{RESUMO}

A produtividade média nacional da batata-doce situa-se, atualmente, bem abaixo do potencial produtivo da cultura, predominando o cultivo de variedades locais e não melhoradas, que propiciam baixos rendimentos. Para melhorar essa condição, além de tratos culturais adequados, faz-se necessária a adoção de cultivares mais produtivos. Por essas razões, o objetivo deste trabalho foi estudar o desempenho de cultivares de batata-doce para caracteres relacionados com o rendimento de raiz. Foram avaliados seis cultivares de batata-doce: Princesa, BRS Amélia, BRS Cuia, Brazlândia Roxa, Beauregard e BRS Rubissol, em um experimento conduzido em Canoinhas-SC. Mudas dos cultivares foram plantadas em condições de campo, nos anos de 2012 e 2013, no delineamento em blocos ao acaso, com três repetições; a parcela experimental foi composta por 11 plantas. Aos 150 dias após o plantio, as plantas de cada parcela foram colhidas e avaliadas para caracteres componentes do rendimento de raiz. De forma geral, os cultivares avaliados constituem boas opções para os produtores, com rendimentos médios acima da média nacional. Os cultivares Beauregard e BRS Rubissol destacam-se dos demais para os caracteres de rendimento de raiz. Os cultivares Princesa, BRS Amélia e BRS Cuia apresentaram desempenho intermediário quanto a raízes comerciais, principalmente no segundo ano de avaliação. O cultivar Brazlândia Roxa teve o pior desempenho para caracteres de rendimento de raiz aos 150 dias após o plantio, provavelmente por apresentar ciclo vegetativo mais longo.

Palavras-chave: Ipomoea batatas (L.) Lam, raízes comerciais, massa de raiz.

\section{ABSTRACT}

\section{Performance of root yield traits in sweet potato cultivars}

In Brazil, the average yield of sweet potato is consistently below the potential of the crop due to the cultivation of local varieties and unimproved genotypes. Increase in yield is achieved by the adoption of appropriate cultural practices and use of more productive cultivars. Thus, the aim of this study was to evaluate the performance of root yield traits in sweet potato cultivars. Six sweet potato cultivars were evaluated: Princesa, BRS Amelia, BRS Cuia, Brazlândia Roxa, Beauregard and BRS Rubissol in an experiment conducted in Canoinhas-SC. These cultivars were planted in the field, in the agricultural years 2012 and 2013, in a randomized block design with three replications and plots consisting of 11 plants. At 150 days after planting, the plants were harvested and the root yield components were evaluated. In general, the cultivars assessed in this study are good choices for sweet potato growers, with yields greater than the country's average. Cultivars Beauregard and BRS Rubissol showed the best results for the traits related to root yield. Cultivars Princesa, BRS Amelia and BRS Cuia showed intermediate performance for commercial roots, especially in the second year of the assessment. The cultivar Brazlândia Roxa had the worst performance for yield root characters at 150 days after planting, which was probably due to its longer cycle.

Key words: Ipomea batatas (L.) Lam, commercial roots, root mass.

\footnotetext{
Submetido em 02/07/2013 e aprovado em 24/06/2015.

'Embrapa Hortaliças/SPM, Canoinhas, Santa Catarina, Brasil. giovani.olegario@embrapa.br

2Embrapa Hortaliças, Brasília, Distrito Federal, Brasil. fabio@cnph.embrapa.br, geovani.amaro@embrapa.br

${ }^{3}$ Embrapa Produtos e Mercado, Canoinhas, Santa Catarina, Brasil. rubens.ponijaleki@embrapa.br

*Autor para correspondência: giovani.olegario@embrapa.br
} 


\section{INTRODUÇÃO}

A batata-doce (Ipomoea batatas (L.) Lam) é a quarta hortaliça mais cultivada no Brasil, sendo produzidas, em 2010, 495,2 mil toneladas, em 41.999 ha (IBGE, 2012). Sua importância econômica e social é resultante da rusticidade, ampla adaptação climática e elevada capacidade de produção de energia em curto espaço de tempo. A origem exata da batata-doce não é conhecida, mas a hipótese americana é normalmente aceita, sendo a região mais provável a faixa compreendida entre o México e o norte da América do Sul.

Essa hortaliça pertence à família Convolvulaceae, sendo I. batatas o único membro hexaploide $(2 \mathrm{n}=6 \mathrm{x}=$ 90). A variabilidade dentro da espécie é muito alta, provavelmente graças ao alto nível de ploidia. Atualmente, observa-se considerável diversidade genética em batata-doce, nas diversas regiões produtoras do Brasil, oriunda de segregação sexuada e assexuada e das introduções de plantas provenientes de outras localidades (Ritschel et al., 2010).

A produtividade média nacional de batata-doce é baixa, de cerca de $11,8 \mathrm{t} \mathrm{ha}^{-1}$, valor bem abaixo do potencial da cultura, que pode ser superior a $40 \mathrm{t} \mathrm{ha}^{-1}$. Com a utilização de manejo adequado podem-se atingir, facilmente, níveis de 25 a $30 \mathrm{t} \mathrm{ha}^{-1}$, em 4 a 5 meses de cultivo (Andrade Júnior et al., 2009; Andrade Júnior et al., 2012). No Brasil, existem 24 cultivares de batata-doce registrados no Ministério da Agricultura, Pecuária e Abastecimento (MAPA, 2013), mas o cultivo de variedades locais e não melhoradas é predominante, sendo, este, o principal fator responsável pelos baixos rendimentos (Cardoso et al., 2005). Portanto, para melhorar essa condição, além do manejo correto de plantio, adubação e demais tratos culturais, faz-se necessária a adoção de cultivares mais produtivos. Além disto, o desempenho de cultivares e de clones de batata-doce quanto a caracteres relacionados com o rendimento de raiz pode variar conforme o ambiente, por serem caracteres de herança quantitativa e de forte influência ambiental (Silva et al., 2012).

Por essas razões, o objetivo deste trabalho foi avaliar o desempenho de cultivares de batata-doce para caracteres relacionados com o rendimento de raiz.

\section{MATERIAL E MÉTODOS}

Os experimentos foram conduzidos em Canoinhas, SC. Foram avaliados seis cultivares de batata-doce: Princesa, BRS Amélia, BRS Cuia, Brazlândia Roxa, Beauregard e BRS Rubissol, em condições de campo, nos anos de 2012 e 2013, com plantio realizado em dezembro de 2011 e dezembro de 2012, respectivamente. O delineamento experimental utilizado em ambos os ensaios foi o de blocos ao acaso, com três repetições, e as parcelas experimentais formadas por uma linha com 11 plantas, espaçadas de $75 \mathrm{~cm}$ entre linhas e de $40 \mathrm{~cm}$ entre plantas $\left(3,30 \mathrm{~m}^{2}\right)$, com uma linha externa de bordadura, em cada bloco, que não foi avaliada.

O plantio foi realizado na mesma área nos dois anos. A adubação em pré-plantio foi realizada com superfosfato triplo (261 kg ha-1) e $\mathrm{KCl}\left(200 \mathrm{~kg} \mathrm{ha}^{-1}\right)$. Não se constataram anormalidades climáticas, como estiagens, granizo, geadas ou ataque de pragas. Foram realizadas capina e amontoa, aos 30 dias após o transplante, e aplicação de ureia, na dose de $120 \mathrm{~kg} \mathrm{ha}^{-1}$. Aos 150 dias após o plantio, foram colhidas e avaliadas as raízes de cada parcela para os caracteres número total de raízes (NTR); número de raízes com padrão comercial (NRC); massa total de raízes (MTR), ou seja, tanto das raízes comerciais como não comerciais; massa fresca de raízes com padrão comercial (MRC) e razão entre MRC e NRC (MMRC). Foram consideradas como raízes comerciais aquelas acima de $10 \mathrm{~cm}$ de comprimento e $5 \mathrm{~cm}$ de diâmetro, que não apresentavam tortuosidade ou embonecamento. Os dados de massa total de raízes e massa de raízes comerciais foram expressos em $\mathrm{t} \mathrm{ha}^{-1}$, para facilitar a comparação com os dados da literatura.

Os dados foram submetidos à análise de variância conjunta para os dois anos e individual e agrupamento de médias, por Skott-Knott a 5\%. Todas estas estimativas foram realizadas por meio do programa GENES (Cruz, 2006).

\section{RESULTADOS E DISCUSSÃO}

Atestou-se, pela análise de variância conjunta, a presença de interação significativa entre cultivares e anos de cultivo, para todos os caracteres avaliados. Sendo assim, os resultados foram discutidos em separado para cada ano. Da mesma forma, todos os valores obtidos para o quadrado médio de tratamentos dos caracteres em estudo para os anos de 2012 e 2013 foram significativos ( $\mathrm{p}<0,05)$, possibilitando diferenciar os cultivares (dados não mostrados).

Muito embora tenha havido interação significativa, ou seja, diferente classificação dos genótipos em cada ano, os valores médios para cada caráter foram bastante semelhantes (Tabela 1). A observação do desempenho de genótipos em mais de um ano agrícola é importante para uma determinação mais consistente do desempenho em determinado local, porque as plantas de batatadoce podem apresentar desempenho diferente de acordo com o ambiente, sendo que genótipos com maior estabilidade de produção são mais previsíveis (Daros \& Amaral Junior, 2000) e, como os caracteres relacionados com o rendimento de raiz podem variar conforme o ambiente, por serem caracteres de herança quantitativa 
e de forte influência ambiental (Silva et al., 2012), pequenas alterações no ambiente, como as de temperatura, umidade do solo ou outros podem influenciar na expressão dessas características.

Os coeficientes de variação fenotípica (CV) apresentaram valores baixos para a maioria dos caracteres, sendo superiores para número de raiz comercial, com valores de $22,41 \%$ para 2012 e 18,88\% para 2013. Da mesma forma, na avaliação de acessos de batata-doce, Silva et al. (2012) verificaram CV para número de tubérculos comerciais de $25,26 \%$. No entanto, para todos os caracteres, a relação entre os coeficientes de variação genético e ambiental $(\mathrm{CVg} / \mathrm{CV})$ foi superior à unidade, indicando predominância da variação de ordem genética sobre a ambiental e boa precisão experimental (Tabela 1). Cavalcante et al. (2009) verificaram predominância de $\mathrm{CVg}$ em relação ao $\mathrm{CV}$ para produtividade de raiz de clones de batata-doce, enquanto Borges et al. (2010) também verificaram predominância de $\mathrm{CVg}$ em relação ao CV para número total de raízes de batata-doce, porém, o CV foi mais importante do que o $\mathrm{CVg}$ para número de raízes comerciais e, principalmente, para peso médio de raízes comerciais.

Extrapolando-se o valor médio do caráter massa total de raízes por parcela para um hectare, obteve-se 31,24 t ha-1, em 2012, e 33,45 t ha $^{-1}$, em 2013, rendimentos esses semelhantes aos obtidos por outros estudos com materiais melhorados (Azevedo et al. 2000; Resende, 2000; Andrade Junior et al., 2009; Andrade Júnior et al., 2012) e bastante superiores ao rendimento médio brasileiro, que é de 11,80 t ha-1 (IBGE, 2012). Portanto, os cultivares testados neste estudo podem ser boas alternativas para os produtores de batata-doce.

Observando-se o desempenho dos cultivares em ambos os cultivos (Tabela 1), verifica-se que as variedades Beauregard e BRS Rubissol destacaram-se quanto ao caráter número total de raízes, indicando grande potencial produtivo, enquanto 'Princesa' apresentou reduzido número total de raízes em ambos os anos.

Quanto à massa total de raízes, 'Beauregard' apresentou o maior rendimento nos ano de 2012 e 2013, agrupando-se com 'BRS Rubissol', neste último ano. Para este caráter, os cultivares Brazlândia Roxa e BRS Amélia mostraram os menores rendimentos, em 2012 e 2013, respectivamente, com variações bastante grandes, no entanto, com o ano de cultivo. Em estudo realizado por Andrade Junior et al. (2009), o cultivar Princesa, colhido aos sete meses após o plantio, produziu 28,78 t $\mathrm{ha}^{-1}$, valor semelhante ao deste trabalho, que foi de 25,72 $\mathrm{t} \mathrm{ha}^{-1}$, na média dos dois anos.

Em relação aos caracteres medidos nas raízes comerciais, observa-se que o cultivar Beauregard desta-

Tabela 1. Agrupamento de médias por Skott-Knott para caracteres fenotípicos avaliados em batata-doce

\begin{tabular}{|c|c|c|c|c|c|}
\hline & \multicolumn{5}{|c|}{ Ano de 2012} \\
\hline & NTR & $\operatorname{MTR}($ t.ha-1) & NRC & $\operatorname{MRC}\left(\right.$ t.ha $\left.^{-1}\right)$ & MMRC (kg) \\
\hline Princesa & $39,00 \mathrm{c}$ & $20,15 \mathrm{~d}$ & $9,00 \mathrm{~b}$ & $11,88 \mathrm{~d}$ & $0,43 \mathrm{c}$ \\
\hline BRS Amélia & $47,33 \mathrm{~b}$ & $32,18 \mathrm{c}$ & $12,00 \mathrm{~b}$ & $19,70 \mathrm{c}$ & $0,54 \mathrm{~b}$ \\
\hline BRS Cuia & $38,67 \mathrm{c}$ & $39,69 \mathrm{~b}$ & $15,33 \mathrm{~b}$ & $30,39 b$ & $0,66 \mathrm{a}$ \\
\hline Braz. Roxa & $27,67 d$ & $6,77 \mathrm{e}$ & $7,67 \mathrm{~b}$ & $8,39 \mathrm{~d}$ & $0,36 \mathrm{~d}$ \\
\hline Beauregard & $86,00 \mathrm{a}$ & $52,88 \mathrm{a}$ & $33,33 \mathrm{a}$ & $38,12 \mathrm{a}$ & $0,39 \mathrm{~d}$ \\
\hline BRS Rubissol & $51,67 \mathrm{~b}$ & $29,00 \mathrm{c}$ & $14,33 \mathrm{~b}$ & $18,72 \mathrm{c}$ & $0,44 \mathrm{c}$ \\
\hline Média & 48,39 & 31,24 & 15,28 & 21,21 & 0,47 \\
\hline $\mathrm{CV}$ & 10,34 & 6,31 & 22,41 & 9,87 & 7,33 \\
\hline \multirow[t]{3}{*}{$\mathrm{CVg} / \mathrm{CV}$} & 3,99 & 7,07 & 2,66 & 5,33 & 3,18 \\
\hline & \multicolumn{5}{|c|}{ Ano de 2013} \\
\hline & NTR & MTR (t.ha-1) & NRC & MRC (kg) & MMRC (g) \\
\hline Princesa & $23,67 \mathrm{c}$ & $31,30 \mathrm{~b}$ & $13,00 \mathrm{~b}$ & $22,42 b$ & $0,58 \mathrm{a}$ \\
\hline BRS Amélia & $22,00 \mathrm{c}$ & $8,63 \mathrm{c}$ & $11,33 b$ & $19,30 \mathrm{~b}$ & $0,56 \mathrm{a}$ \\
\hline BRS Cuia & $44,33 \mathrm{~b}$ & $26,15 b$ & $26,00 \mathrm{a}$ & $20,60 \mathrm{~b}$ & $0,27 \mathrm{~b}$ \\
\hline Braz. Roxa & $41,00 \mathrm{~b}$ & $23,24 \mathrm{c}$ & $13,33 b$ & $13,54 \mathrm{c}$ & $0,34 \mathrm{~b}$ \\
\hline Beauregard & $46,33 \mathrm{~b}$ & $46,45 \mathrm{a}$ & $24,00 \mathrm{a}$ & $34,63 \mathrm{a}$ & $0,48 \mathrm{a}$ \\
\hline BRS Rubissol & $55,67 \mathrm{a}$ & $43,12 \mathrm{a}$ & $27,33 \mathrm{a}$ & $31,51 \mathrm{a}$ & $0,38 \mathrm{~b}$ \\
\hline Média & 38,83 & 33,45 & 19,17 & 23,66 & 0,44 \\
\hline $\mathrm{CV}$ & 12,99 & 5,55 & 18,88 & 8,22 & 14,61 \\
\hline $\mathrm{CVg} / \mathrm{CV}$ & 2,58 & 4,98 & 1,95 & 4,04 & 1,87 \\
\hline
\end{tabular}

NTR: número total de raízes; MTR: massa total de raízes; NRC: número de raízes com padrão comercial; MRC: massa de raízes com padrão comercial; MMRC: massa média de raízes com padrão comercial. Médias seguidas de letras diferentes na coluna diferiram, a 5\% de probabilidade, pelo teste de Skott-Knott. 
cou-se, em 2012, para número e massa de raízes. Entretanto, este cultivar não apresentou os maiores valores para massa média de raízes comerciais, nesse ano, com média de 390 g. O bom desempenho quanto a estes caracteres repetiu-se em 2013, juntamente com o do cultivar BRS Rubissol. É importante salientar que o cultivar Beauregard é rico em $\beta$-caroteno e destaca-se pelo elevado potencial produtivo e precocidade. Em trabalho realizado por Schultheis et al. (1999), na Carolina do Norte, EUA, foi verificado que a melhor época de colheita ocorreu entre 100 a 110 dias, sendo que aos 90 dias já foi possível colher raízes com tamanho comercial. Esses autores obtiveram rendimentos totais variando de 25,5 a 34,9 $\mathrm{t} \mathrm{ha}^{-1}$, para esse cultivar, aos 132 dias após o plantio.

Quanto à massa média de raízes comerciais, o valor médio apresentado pelos cultivares, neste trabalho, foi de 470 g, em 2012, e de 440 g, em 2013; valores pouco acima do tamanho ideal para o comércio, que seria entre 200 a 400 g, de acordo com Miranda (1989), indicando que, para esses cultivares, a data de colheita poderia ser adiantada, muito embora o tamanho ideal possa variar conforme as exigências do mercado (Queiroga et al. 2007). Azevedo et al. (2000) reportaram massa média de tubérculos comerciais, variando de 123,3 a 261,4 g, para um ciclo de seis meses. Resende (2000), com ciclo de 200 dias, observou massa média de tubérculos comerciais de 387,2 e 381,0 g para os cultivares Brazlândia Roxa e Princesa respectivamente. Já Andrade Junior et al. (2009), com um ciclo de sete meses, verificaram massa média de raízes comerciais, variando de 182,94 g a 320,95 g, e valores de 199,14 g e 233,84 g para Princesa e Brazlândia Roxa, respectivamente, enquanto, na média dos dois anos, foram verificadas, neste estudo, massas médias de $350 \mathrm{~g}$ e de $500 \mathrm{~g}$, para esses dois cultivares, respectivamente; ou seja, valores superiores aos dos estudos acima relatados.

Os cultivares Princesa, BRS Amélia e BRS Cuia apresentaram desempenho intermediário, quanto a raízes comerciais, principalmente em 2013. Já 'Brazlândia Roxa' teve baixo rendimento de raízes comerciais em ambos os cultivos. Para massa de raízes comerciais foram obtidos, neste trabalho, na média dos dois anos, $17,15 \mathrm{t} \mathrm{ha}^{-1}$ e 19,96 t ha ${ }^{-1}$, para os cultivares Princesa e Brazlândia Roxa, enquanto Andrade Junior et al. (2009) verificaram valores de 25,87 $\mathrm{t} \mathrm{ha}^{-1}$ e de 19,70 $\mathrm{tha}^{-1}$, para esses cultivares, colhidos aos sete meses após o plantio.

Mendonça \& Peixoto (1991), no centro-oeste brasileiro, com colheita aos 150 dias, obtiveram produção total de raízes, para Brazlândia Roxa, de 20,21 t ha ${ }^{-1}$, valor semelhante ao obtido neste trabalho para o ano de $2013\left(23,24 \mathrm{t} \mathrm{ha}^{-1}\right)$. No entanto, rendimento inferior foi obtido por Resende (2000), que avaliou cultivares e épocas de colheita, quanto à qualidade e produtividade de raízes, e verificou que aos 150 dias o cultivar Brazlândia Roxa apresentou reduzido rendimento total de raízes (14,3 t ha $\left.{ }^{-1}\right)$ e concluiu que, para os cultivares Brazlândia Roxa e Princesa, seriam necessários ciclos vegetativos acima de 150 dias, para haver maior rendimento.

Além disto, Resende (1999) verificou que, na média de dois experimentos, o rendimento total de raízes, aos 150 dias, foi de 15,65 tha ${ }^{-1}$ para 'Princesa', e de 10,85 t, ha-1, para 'Brazlândia Roxa', rendimentos inferiores à média do experimento, principalmente em relação ao último cultivar. Esse autor comenta que, além de excelente aspecto comercial, 'Brazlândia Roxa' apresenta boa resistência a insetos de solo e ao nematoide das galhas e que um ciclo maior do que 150 dias poderia ser avaliado. Neste sentido, aos seis meses após o plantio, Andrade Júnior et al. (2012) verificaram uma produção total de raízes de $17,1 \mathrm{t} \mathrm{ha}^{-1}$, enquanto Andrade Junior et al. (2009), com sete meses de ciclo, obtiveram rendimento total de 22,38 $\mathrm{t} \mathrm{ha}^{-1}$ para esse cultivar.

O ciclo vegetativo dos cultivares pode variar conforme o ambiente de cultivo, dependendo da temperatura ou do fotoperíodo; são, portanto, importantes, mais estudos de adaptação a determinado local de cultivo. Cabe também ressaltar que o tamanho ideal das raízes, e, portanto, a época ideal de colheita, podem variar conforme o mercado consumidor (Queiroga et al. 2007). Pode-se verificar, neste estudo, que o ciclo de 150 dias foi suficiente para que o cultivar mais precoce Beauregard apresentasse elevado rendimento de raízes e massa média adequada para o comércio, entre 390 e 480 gramas; e está de acordo com as recomendações técnicas para os cultivares BRS Amélia, BRS Cuia e BRS Rubissol, que devem ser colhidos a partir de 120 a 140 dias e, para os cultivares Brazlândia Roxa e Princesa, que podem ser colhidos a partir de 150 dias. Muito embora haja indicações, neste experimento, de que, para as condições do ambiente testado para a cultivar Brazlândia Roxa, um ciclo maior que 150 dias poderia ter proporcionado maior rendimento.

\section{CONCLUSÕES}

Os cultivares Beauregard e BRS Rubissol destacamse dos demais para os caracteres de rendimento de raiz.

Os cultivares Princesa, BRS Amélia e BRS Cuia apresentaram desempenho intermediário quanto a raízes comerciais, principalmente no segundo ano de avaliação.

O cultivar Brazlândia Roxa teve o pior desempenho para caracteres de rendimento de raiz aos 150 dias após o plantio, provavelmente por apresentar ciclo vegetativo mais longo que o dos demais. 


\section{REFERÊNCIAS}

Andrade Junior VC, Viana DJS, Fernandes JSC, Figueiredo JÁ, Nunes UR \& Neiva IP (2009) Selection of sweet potato clones for the region Alto Vale do Jequitinhonha. Horticultura Brasileira, 27:389-393.

Andrade Júnior VC, Viana DJS, Pinto NAVD, Ribeiro KG, Pereira RC, Neiva IP, Azevedo AM \& Andrade PCR (2012) Características produtivas e qualitativas de ramas e raízes de batata-doce. Horticultura Brasileira, 30:584-589.

Azevedo SM, Freitas JÁ, Maluf WR \& Silveira MA (2000) Desempenho de clones e métodos de plantio de batata-doce. Acta Scientiarum, 22:901-905

Borges V, Ferreira PV, Soares L, Santos GM \& Santos AMM (2010) Seleção de clones de batata-doce pelo procedimento REML/ BLUP. Acta Scientiarum Agronomy, 32:643-649.

Cardoso AD, Viana AES, Ramos PAS, Matsumoto SN, Amaral CLF, Sediyama T \& Morais OM (2005) Avaliação de clones de batatadoce em Vitória da Conquista. Horticultura Brasileira, 23:911-914.

Cavalcante M, Ferreira PV, Paixão SL, Costa JG, Pereira RG \& Madalena JAS (2009) Potenciais produtivo e genético de clones de batatadoce. Acta Scientiarum, 31:421-426.

Cruz CD (2006) Programa Genes: biometria. Viçosa, Editora UFV. 382p.

Daros M \& Amaral Junior AT (2000) Adaptabilidade e estabilidade de produção de Ipomoea batatas. Acta Scientiarum. Agronomy, 22:911917.

IBGE - Instituto Brasileiro de Geografia e Estatística (2012) Produção Agrícola Municipal 2010: informações sobre culturas temporárias. Rio de Janeiro: IBGE. Disponível em: <http://www.sidra.ibge.gov.br/ bda/pesquisas/pam/default.asp $>$. Acessado em: 02 de fevereiro de 2012.
MAPA - Ministério da Agricultura, Pecuária e Abastecimento (2013) Cultivares de batata-doce registradas - Brasília. Disponível em: <http:/ /extranet.agricultura.gov.br/php/snpc/cultivarweb/ cultivares_registradas.php>. Acessado em: 24 de maio de 2013.

Mendonça ATC \& Peixoto N (1991) Efeito do espaçamento e de níveis de adubação em cultivares de batata doce. Horticultura Brasileira, 9:80-82.

Miranda JEC de (1989) Brazlândia Roxa, Brazlândia Branca, Brazlândia Rosada e Coquinho: novas cultivares de batata-doce. Horticultura Brasileira, 7:32-33.

Queiroga RCF, Santos MA, Menezes MA, Vieira CPG \& Silva MC (2007) Fisiologia e produção de cultivares de batata-doce em função da época de colheita. Horticultura Brasileira, 25:371-374.

Resende GM de (1999) Características produtivas de cultivares de batata-doce sob condições irrigadas e de sequeiro na região norte de Minas Gerais. Horticultura Brasileira, 17:151-154.

Resende GM (2000) Características produtivas de cultivares de batatadoce em duas épocas de colheita, em Porteirinha - MG. Horticultura Brasileira, 18:68-71.

Ritschel OS, Lopes CA, Huamán Z, Ferreira ME, Franca FJ, Menêzes JE, Teixeira DMC, Torres AC, Charchar JM \& Thomazelli L (2010) Organização do banco ativo de germoplasma de batata-doce: situação atual e perspectivas. In: Queiroz MA de, Goedert CO \& Ramos SRR (Eds.) Recursos genéticos e melhoramento de plantas para o Nordeste brasileiro: versão 1.0. Disponível em: <http:www.cpatsa.embrapa.br>. Acessado em: 26 de agosto de 2013.

Schultheis JR, Walters SA, Adams DE \& Estes EA (1999) In row plant spacing and date of harvest of 'Beauregard' sweetpotato affect yield and return on investment. HortScience, 34:1229-1233.

Silva GO, Ponijaleki R \& Suinaga FA (2012) Divergência genética entre acessos de batata-doce utilizando caracteres fenotípicos de raiz. Horticultura Brasileira, 30:595-599. 